\title{
PENGARUH STRATEGI NATION BRANDING "WONDERFUL INDONESIA" TERHADAP PROSES KEPUTUSAN BERKUNJUNG WISATAWAN AUSTRALIA KE INDONESIA
}

\author{
Sri Utami \\ Vanessa Gaffar \\ Manajemen Pemasaran Pariwisata FPIPS UPI
}

\begin{abstract}
ABSTRAK
Sebagai industri yang diperdagangkan secara internasional dan berkembang pesat, pariwisata menjadi salah satu kategori utama dalam sektor perekonomian. Bagi Indonesia, pariwisata merupakan salah satu sumber utama penghasilan devisa serta dapat menciptakan lapangan kerja dan peluang untuk pengembangan lebih lanjut. Australia merupakan salah satu dari tiga target utama pangsa pasar pariwisata dan juga merupakan salah satu penyumbang wisatawan terbesar di Indonesia. Program nation branding merupakan salah satu strategi Kementerian Pariwisata dan Ekonomi kreatif (Kemenparekraf) untuk meningkatkan jumlah kunjungan wisatawan, yaitu dengan mengembangkan strategi dan koordinasi kampanye pariwisata melalui nation branding. Nation branding adalah menerapkan branding dan teknik komunikasi pemasaran untuk mempromosikan citra suatu bangsa yang nantinya akan berpengaruh pada jumlah kunjungan wisatawan. Dalam penelitian ini, variabel bebas $(X)$ yang digunakan yaitu Nation Branding yang terdiri dari tourism, people, dan culture and heritage. Variabel terikat $(Y)$ yaitu proses keputusan berkunjung. Jenis penelitian yang digunakan deskriptif verifikatif, dan metode yang digunakan adalah survei dengan teknik stratified random sampling, maka diperoleh jumlah sampel sebesar 120 responden. Teknik analisis data dan uji hipotesis yang digunakan adalah path analysis (analisis jalur). Hasil penelitian menunjukkan bahwa variabel nation branding memberikan pengaruh yang signifikan terhadap proses keputusan berkunjung.
\end{abstract}

Kata kunci: nation branding, proses keputusan berkunjung, Indonesia

\section{PENDAHULUAN}

Selama beberapa dekade terakhir, pariwisata telah mengalami perkembangan dan perubahan yang membuat pariwisata menjadi salah satu industri tercepat dan terbesar yang menggerakkan perekonomian. Menurut World Tourism Organization pariwisata akan terus berkembang pada periode 2010-2030 yang arah perkembangannya akan lebih signifikan, dengan jumlah kedatangan wisatawan mancanegara (wisman) di seluruh dunia akan meningkat rata-rata 3,3\% per tahun. Bagi negara berkembang, pariwisata merupakan salah satu sumber utama penghasilan devisa serta dapat menciptakan lapangan kerja dan peluang untuk pengembangan lebih lanjut.

Berdasarkan data yang diambil dari UNWTO dalam hal pembagian pangsa pasar (market share) wisman di dunia, semua kawasan mengalami peningkatan kunjungan wisman pada tahun 2012 kecuali kawasan Middle East yang mengalami penurunan, dengan Eropa menjadi kawasan yang paling diminati wisman baik pada tahun 2011 maupun tahun 2012, hal ini disebabkan karena Eropa meraih pangsa pasar sebesar $51,7 \%$ dari pangsa pasar dunia.

Kawasan Asia Pasifik menempati peringkat kedua pada pangsa pasar dunia baik pada tahun 2011 maupun tahun 2012 dan meraih pangsa pasar sebesar $22,5 \%$ dari pangsa pasar di dunia. Asia Pasifik mengalami peningkatan kunjungan wisman yang lebih tinggi dibandingkan dengan peningkatan pada kunjungan ke Eropa, Asia Pasifik mengalami perubahan peningkatan sebesar 6,8 \% sedangkan Eropa hanya mengalami peningkatan sebesar 3,3\%.

Dalam kawasan Asia Pasifik itu sendiri masih terbagi ke dalam beberapa kawasan, yaitu North-East Asia, South-East Asia, Oceania, dan South Asia. Peringkat tertinggi kunjungan wisman diraih oleh North-East Asia (Jepang, Korea, Cina, Taiwan, Hongkong dan Mongalia) dengan market share sebesar 11,9 \% dan South-East Asia (Malaysia, Indonesia, Thailand, Kamboja, Vietnam dsb) di peringkat kedua dengan market share sebesar 8,1 \%. Kawasan Oceania (Australia, New Zealand, Papua New Guinea dan Kepulauan Pasifik) dan South Asia (Bangladesh, Bhutan, India, Nepal dsb) meraih market share dengan 
jumlah $1,2 \%$ dan $1,4 \%$. Pembagian market dari Tabel 1.1 berikut.

share di kawasan Asia Pasifik dapat dilihat

TABEL 1.1

MARKET SHARE KAWASAN ASIA PASIFIK TAHUN 2010, 2011 dan 2012

\begin{tabular}{|c|c|c|c|c|c|}
\hline & \multicolumn{3}{|c|}{$\begin{array}{c}\text { International Tourist } \\
\text { Arrivals (Million) }\end{array}$} & \multirow{2}{*}{$\begin{array}{c}\text { Market } \\
\text { Share } \\
(\%)\end{array}$} & \multirow{2}{*}{$\begin{array}{c}\text { Change } \\
(\%) \\
12 / 11\end{array}$} \\
\hline & 2010 & 2011 & 2012 & & \\
\hline World & 952 & 996 & 1,035 & 100 & 3.8 \\
\hline Europe & 487.6 & 517.5 & 534.8 & 51.7 & 3.3 \\
\hline Asia Pacific & 205.1 & 218.1 & 232.9 & 22.5 & 6.8 \\
\hline Americas & 150.3 & 156.3 & 162.1 & 15.7 & 3.7 \\
\hline Africa & 49.8 & 49.2 & 52.3 & 5.1 & 6.3 \\
\hline Middle East & 59.2 & 55.3 & 52.6 & 5.1 & -4.9 \\
\hline
\end{tabular}

Sumber : Modifikasi dari World Tourism Organization, Januari 2013

Dalam kawasan Asia Pasifik itu sendiri masih terbagi ke dalam beberapa kawasan, yaitu North-East Asia, South-East Asia, Oceania, dan South Asia. Peringkat tertinggi kunjungan wisman diraih oleh North-East Asia (Jepang, Korea, Cina, Taiwan, Hongkong dan Mongalia) dengan market share sebesar 11,9 \% dan South-East Asia (Malaysia, Indonesia, Thailand, Kamboja,
Vietnam dsb) di peringkat kedua dengan market share sebesar 8,1 \%. Kawasan Oceania (Australia, New Zealand, Papua New Guinea dan Kepulauan Pasifik) dan South Asia (Bangladesh, Bhutan, India, Nepal dsb) meraih market share dengan jumlah $1,2 \%$ dan $1,4 \%$. Pembagian market share di kawasan Asia Pasifik dapat dilihat dari Tabel 1.2 berikut.

TABEL 1.2

MARKET SHARE KAWASAN ASIA PASIFIK TAHUN 2010,2011 dan 2012

\begin{tabular}{|l|c|c|c|c|c|}
\hline & \multicolumn{3}{|c|}{$\begin{array}{c}\text { International Tourist } \\
\text { Arrivals (Million) }\end{array}$} & $\begin{array}{c}\text { Market } \\
\text { Share } \\
(\%)\end{array}$ & $\begin{array}{c}\text { Change } \\
(\%) \\
\mathbf{1 2 / 1 1}\end{array}$ \\
\cline { 2 - 6 } & $\mathbf{2 0 1 0}$ & $\mathbf{2 0 1 1}$ & $\mathbf{2 0 1 2}$ & $\mathbf{2 0 1 2}$ & \\
\hline Asia Pacific & 205.1 & 218.1 & 233 & 22.5 & 6.8 \\
\hline North-East Asia & 111.5 & 115.8 & 122.8 & 11.9 & 6 \\
\hline South-East Asia & 70 & 77.3 & 84 & 8.1 & 8.7 \\
\hline Oceania & 11.6 & 11.7 & 12.1 & 1.2 & 4 \\
\hline South Asia & 12 & 13.4 & 14 & 1.4 & 4.4 \\
\hline
\end{tabular}

Sumber : Modifikasi dari World Tourism Organization, Januari 2013

Berdasarkan data pembagian pangsa pasar di kawasan Asia Pasifik, walaupun South-East Asia berada pada peringkat kedua dalam pangsa pasar wisman, tetapi kenaikan dari jumlah kunjungan wisatawannya cukup tinggi. Bisa dikatakan bahwa Asia yang kebanyakan terdiri dari negara-negara berkembang juga mempunyai perkembangan pariwisata yang baik, hal ini dapat dilihat dari peningkatan wisman yang berkunjung ke Asia.
The Travel \& Tourism Competitiveness Report 2013 yang menjelaskan secara lebih detail tentang persaingan pariwisata di Eropa, Amerika, Afrika dan juga Asia Pasifik, dikatakan bahwa Singapura menduduki peringkat pertama dalam daya saing pariwisata dan perjalanan di Asia Pasifik dan Malaysia meraih peringkat ke-8, sedangkan Indonesia meraih posisi ke-12. 
TABEL 1.3

DAYA SAING PERJALANAN DAN WISATA NEGARA ASEAN

\begin{tabular}{|l|c|c|c|c|c|}
\hline Negara & $\begin{array}{c}\text { Peringkat } \\
\text { di Dunia } \\
\mathbf{2 0 0 9}\end{array}$ & $\begin{array}{c}\text { Peringkat } \\
\text { di Dunia } \\
\mathbf{2 0 1 1}\end{array}$ & $\begin{array}{c}\text { Peringkat } \\
\text { di Dunia } \\
\mathbf{2 0 1 3}\end{array}$ & $\begin{array}{c}\text { Peringkat di } \\
\text { Asia Pasifik } \\
\mathbf{2 0 1 1}\end{array}$ & $\begin{array}{c}\text { Peringkat di } \\
\text { Asia Pasifik } \\
\mathbf{2 0 1 3}\end{array}$ \\
\hline Singapura & 10 & 10 & 10 & 1 & 1 \\
\hline Malaysia & 32 & 35 & 34 & 7 & 8 \\
\hline Thailand & 39 & 41 & 43 & 10 & 9 \\
\hline Brunei & 69 & 67 & 72 & 11 & 13 \\
\hline Indonesia & $\mathbf{8 1}$ & $\mathbf{7 4}$ & $\mathbf{7 0}$ & $\mathbf{1 3}$ & $\mathbf{1 2}$ \\
\hline Vietnam & 89 & 80 & 80 & 14 & 16 \\
\hline Filipina & 86 & 94 & 82 & 18 & 17 \\
\hline Kamboja & 108 & 109 & 106 & 21 & 20 \\
\hline
\end{tabular}

Sumber : Modifikasi dari The Travel \& Tourism Competitiveness Report 2013

Dilihat dari tabel di atas, Indonesia mengalami peningkatan daya saing di tahun 2013 jika dibandingkan dengan tahun sebelumnya dan mengalahkan Brunei. Menurut Forum Ekonomi Dunia, Indeks Daya Saing Perjalanan dan Wisata mengukur faktor-faktor dan kebijakan yang dibuat untuk pengembangan sektor pariwisata di negara-negara yang berbeda dengan menggunakan 13 ukuran, yaitu kebijakan peraturan regulasi, regulasi lingkungan, keselamatan dan keamanan, kesehatan dan kebersihan, infrastruktur transportasi, serta natural sources yang ada.

TABEL 1.4

KUNJUNGAN WISMAN BULANAN KE INDONESIA PADA TAHUN 2010, 2011 dan 2012

\begin{tabular}{|c|c|c|c|c|}
\hline Bulan & $\mathbf{2 0 1 0}$ & $\mathbf{2 0 1 1}$ & $\mathbf{2 0 1 2}$ & $\mathbf{( + / - )} \%$ \\
\hline Januari & 493.799 & 548.821 & 652.692 & 18,9 \\
\hline Februari & 523.135 & 568.057 & 592.502 & 4,3 \\
\hline Maret & 594.242 & 598.068 & 658.602 & 10,1 \\
\hline April & 555.915 & 608.093 & 626.100 & 2,9 \\
\hline Mei & 600.031 & 600.191 & 650.883 & 8,4 \\
\hline Juni & 613.422 & 674.402 & 695.531 & 3,1 \\
\hline Juli & 658.476 & 745.451 & 701.200 & $-5,9$ \\
\hline Agustus & 586.530 & 621.084 & 634.194 & 2,1 \\
\hline September & 560.367 & 650.071 & 683.584 & 5,2 \\
\hline Oktober & 594.654 & 656.006 & 688.341 & 5 \\
\hline November & 578.152 & 654.948 & 693.867 & 6 \\
\hline Desember & 644.221 & 724.539 & 766.966 & 6 \\
\hline $\begin{array}{c}\text { Grand } \\
\text { Total }\end{array}$ & $\mathbf{7 . 0 0 2 . 9 4 4}$ & $\mathbf{7 . 6 4 9 . 7 3 1}$ & $\mathbf{8 . 0 4 4 . 4 6 2}$ & $\mathbf{5 , 2}$ \\
\hline
\end{tabular}

Sumber : Website Budaya Pariwisata

Tercatat hingga bulan Desember 2012 kunjungan wisman ke Indonesia menunjukkan peningkatan jika dibandingkan dengan periode yang sama pada tahun sebelumnya kecuali pada bulan Juli 2012 yang mengalami penurunan sebesar 6\% yang disebabkan adanya krisis Eropa, bulan puasa dan penyelenggaraan Olimpiade London 2012.

TABEL 1.5

KUNJUNGAN WISMAN BERDASARKAN KEBANGSAAN

\begin{tabular}{|l|l|r|r|r|c|}
\hline No & Nationality & \multicolumn{1}{|c|}{$\mathbf{2 0 1 0}$} & $\mathbf{2 0 1 1}$ & \multicolumn{1}{c|}{$\mathbf{2 0 1 2}$} & Growth $(\boldsymbol{\%})$ \\
\hline 1. & Singapura & 1.128 .731 & 1.248 .469 & 1.437 .225 & 15,11 \\
\hline 2. & Malaysia & 1.033 .435 & 1.036 .947 & 1.261 .347 & 21,64 \\
\hline 3. & Australia & 730.895 & 886.446 & 993.813 & 12,11 \\
\hline 4. & Cina & 469.365 & 453.827 & 665.504 & 46,64 \\
\hline
\end{tabular}




\begin{tabular}{|l|l|l|l|l|l|}
\hline 5. & Jepang & 418.971 & 381.318 & 485.846 & 27,41 \\
\hline
\end{tabular}

Sumber : Modifikasi dari Website Budaya Pariwisata,

Kunjungan wisman ke Indonesia Dari negara-negara ini, tiga diantaranya berdasarkan kebangsaan, Singapura menjadi penyumbang devisa terbesar, yaitu menempati peringkat pertama dan terlihat Singapura, Malaysia,dan Australia, dengan menunjungan pertumbuhan sebesar 15.11 dua pintu masuk utama yaitu, Bandara persen. Dilihat dari kebangsaan, wisman Soekarno-Hatta Jakarta dan Ngurah Rai yang datang ke Indonesia pada umumnya Bali. Jumlah kunjungan wisatawan merupakan wisman ASEAN. Saat ini ada 16 berdasarkan dua pintu masuk utama pada negara yang menjadi fokus pasar pariwisata tahun 2012 dapat dilihat pada Tabel 1.6 Indonesia, di antaranya Singapura, Malaysia, Australia, Jepang, Cina, Korea, dan Filipina. berikut.

TABEL 1.6

KUNJUNGAN WISMAN BERDASARKAN DUA PINTU MASUK UTAMA

\begin{tabular}{|c|c|c|c|}
\hline \multirow[b]{2}{*}{ No. } & \multirow[b]{2}{*}{ Negara } & \multicolumn{2}{|c|}{ Dua Pintu Masuk Utama } \\
\hline & & $\begin{array}{c}\text { Soekarno-Hatta } \\
\text { Jakarta }\end{array}$ & $\begin{array}{c}\text { Ngurah Rai } \\
\text { Bali }\end{array}$ \\
\hline 1 & Singapura & 178.650 & 117.226 \\
\hline 2 & Malaysia & 310.211 & 169.490 \\
\hline 3 & Australia & 84.161 & 786.535 \\
\hline 4 & Cina & 207.196 & 317.126 \\
\hline 5 & Jepang & 195.967 & 188.419 \\
\hline
\end{tabular}

Sumber : Modifikasi dari Website Budaya Pariwisata,

Sampai pada tahun 2012 wisatawan asing yang datang ke Indonesia masih didominasi oleh wisatawan ASEAN dan Australia, melihat dari banyaknya jumlah wisatawan tersebut maka Kementrian Pariwisata dan Ekonomi Kreatif
(Kemenparekraf) dalam Rapat Kordinasi Sinkronisasi Program Pemasaran Pariwisata 2013 menetapkan target atau fokus pasar wisman. Target wisman pada tahun 2013 menurut tiga peringkat teratas dapat dilihat pada Tabel 1.7 berikut.

TABEL 1.7

TARGET WISATAWAN MANCANEGARA 2013

\begin{tabular}{|c|c|c|c|l|}
\hline & \multirow{2}{*}{ Fokus } & \multicolumn{3}{|c|}{ Target 2013 } \\
\cline { 3 - 5 } No. & Pasar & Optimis & Moderat & Pesimis \\
\hline $\mathbf{1}$ & Singapura & 1.750 .000 & 1.680 .000 & 1.625 .000 \\
\hline $\mathbf{2}$ & Malaysia & 1.400 .000 & 1.340 .000 & 1.290 .000 \\
\hline $\mathbf{3}$ & Australia & 1.220 .000 & 1.170 .000 & 1.125 .000 \\
\hline
\end{tabular}

Sumber: Paparan Direktorat Jenderal Pemasaran Pariwisata (2012)

Dilihat dari target wisman yang ditentukan, kebanyakan wisatawan berasal dari kawasan ASEAN yang masih berada di wilayah dan memiliki ras yang sama, yaitu Asia. Wisatawan Australia itu sendiri berbeda dengan wisatawan dari wilayah Asia, perbedaan bisa terlihat dari karakteristik mereka, gaya berwisata mereka, gaya hidup dan lainnya. Melihat peningkatan wisawatan Australia yang lebih kecil dibandingkan dengan persentase pertumbuhan wisatawan ASEAN lainnya, pariwisata Indonesia seharusnya mempunyai peluang dan potensi yang sangat besar jika dibandingkan dengan negara-negara lain di Asia Tenggara. Dalam upaya meraih dan meningkatkan target kunjungan wisatawan Australia ke Indonesia dan bersaing dengan negara ASEAN lainnya, pemerintah lebih gencar mempromosikan nation branding "Wonderful Indonesia" agar mampu bersaing dengan negara lain, dan memberikan persepsi yang lebih baik di mata wisatawan Australia, persepsi yang 
baik akan mempengaruhi jumlah kunjungan wisatawan. Strategi yang diterapkan dapat dilihat di Tabel 1.8 berikut.

TABEL 1.8

STRATEGI DAN KEBIJAKAN PEMASARAN PARIWISATA INDONESIA

\begin{tabular}{|c|c|c|}
\hline \multicolumn{2}{|c|}{ Strategi Pemasaran Pariwisata Indonesia } & Keterangan \\
\hline $\begin{array}{l}\text { Strategi } \\
\text { Pemasaran } \\
\text { Terpadu }\end{array}$ & $\begin{array}{ll}\text { 1. } & \text { Penyebarluasan Wonderful } \\
& \text { Indonesia (nation branding) } \\
\text { 2. } & \text { Product Match Market } \\
\text { 3. } & \text { Segmented Product } \\
\text { 4. } & \text { Perkuatan Sosialisasi Kegiatan } \\
& \text { Pemasaran } \\
\text { 5. } & \text { Perluasan Jaringan Mitra Operator } \\
\text { Luar Negeri } & \\
\text { 6. Pembentukan Visit Indonesia } \\
\text { Tourism Office (VITO)di fokus- } \\
\text { fokus pasar }\end{array}$ & $\begin{array}{l}\text { Mengembangkan strategi dan } \\
\text { koordinasi kampanye nation } \\
\text { branding Indonesia } \\
\text { 1. Vertical Marketing: } \\
\text { 2. Horizontal Marketing: }\end{array}$ \\
\hline $\begin{array}{l}\text { Kebijakan } \\
\text { Pemasaran }\end{array}$ & $\begin{array}{ll}\text { 1. } & \text { Peningkatan Citra } \\
\text { 2. } & \text { Promosi dan Fasilitasi } \\
\text { 3. } & \text { Penjualan Promosi Destinasi }\end{array}$ & $\begin{array}{l}\text { Partisipasi pada Bursa } \\
\text { Internasional, Direct Selling, } \\
\text { Festival Indonesia, } \\
\text { Penyelenggaraan Event } \\
\text { Pariwisata, Operasionalisasi } \\
\text { VITO, Co-Marketing Event } \\
\text { Pariwisata Daerah }\end{array}$ \\
\hline
\end{tabular}

Sumber: Modifikasi Paparan Wamen dan Paparan Promosi Wilayah Amerika dan Pasifik, Kemenparekraf 2012

Tabel 1.8 diatas merupakan strategi dan kebijakan yang telah dibuat oleh Kemenparekraf dalam rangka meningkatkan jumlah kunjungan wisatawan dengan menetapkan sasaran sebanyak 9 juta wisatawan di tahun 2013. Sebuah nation brand di suatu negara seharusnya ada, dengan atau tanpa kesadaran upaya dalam membuat nation brand, sebagaimana setiap negara saat ini mempunyai masing-masing citra di mata audiens internasional, baik itu kuat atau lemah, jelas atau samar. Pendekatan terhadap brand ini mempertahankan karakteristik Indonesia yang sudah melekat di benak masyarakat dan juga diharapkan akan mendukung program-program pemasaran pariwisata yang akan datang. Peningkatan citra melalui strategi nation branding ini akan mempengaruhi persepsi wisatawan yang nantinya akan menjadi pertimbangan untuk menentukan keputusan wisatawan berkunjung ke Indonesia karena pemilihan tujuan wisata tentunya terjadi melalui proses keputusan berkunjung yang dilakukan oleh wisatawan. Sehingga dalam prosesnya wisatawan dihadapkan dalam berbagai pilihan kebutuhan untuk berwisata yang dipengaruhi faktor-faktor yang relevan.
Berdasarkan data yang diperoleh, maka perlu dilakukan penelitian dengan judul "Pengaruh Strategi Nation Branding “Wonderful Indonesia” Terhadap Proses Keputusan Berkunjung Wisatawan Australia Ke Indonesia"

\section{B. Rumusan Masalah}

Berdasarkan latar belakang di atas, maka dapat dirumuskan masalah penelitian sebagai berikut :

1. Bagaimanakah gambaran nation branding "Wonderful Indonesia".

2. Bagaimanakah gambaran proses keputusan berkunjung wisatawan Australia yang berkunjung ke Indonesia.

3. Seberapa besar pengaruh nation branding "Wonderful Indonesia" yang terdiri dari people, tourism, culture dan heritage terhadap proses keputusan berkunjung wisatawan Australia untuk berkunjung ke Indonesia.

\section{Tujuan Penelitian}

Berdasarkan dari rumusan masalah di atas, maka tujuan dari penelitian ini adalah untuk memperoleh hasil temuan mengenai :

1. Nation branding "Wonderful Indonesia" yang terdiri dari people, tourism, culture dan heritage. 
2. Proses keputusan berkunjung wisatawan yang berkunjung ke Indonesia.

3. Pengaruh nation branding "Wonderful Indonesia" yang terdiri dari people, tourism, culture dan heritage terhadap proses keputusan berkunjung wisatawan ke Indonesia.

\section{KAJIAN PUSTAKA}

Industri pariwisata merupakan industri yang sangat berkembang dan saling bersaing, maka diperlukan adanya pemasaran untuk membantu mengidentifikasi dan memenuhi kebutuhan target pasar yang terus berubah dan bertambah. Sejalan dengan perkembangan perekonomian, konsumen sudah tidak melakukan keputusan pembelian hanya melihat dari produknya saja tetapi sudah mulai pada tahap pemilihan merek atau brand. Brand yang kuat bukan hanya diperuntukkan untuk produk manufaktur saja tetapi juga produk pariwisata seperti tujuan destinasi atau negara.

Menurut Hermawan Kartajaya (2005:38) memasarkan daerah merupakan mendesain suatu daerah agar mampu memenuhi keinginan pelanggannya. Strategic Place Triangle ini merupakan grand design dari strategi pemasaran daerah. Bukan hanya tempat, destinasi, dan kota saja yang bisa mempunyai sebuah brand, sekarang ini negara-negara di dunia saling bersaing dalam hal menarik wisatawan melalui strategi pemasaran nation branding. Dalam Strategic Place Triangle menurut Hermawan Kartajaya terdiri dari Positioning, Differentiation, dan Brand.

Dalam pemasaran sebuah destinasi atau negara Simon Anholt menyatakan bahwa nation branding termasuk dalam brand. Nation branding merupakan sebuah realitas yang komplek dari suatu negara dengan cara merangkum budaya, sejarah, masyarakat, pemerintah dalam suatu gambar dan logo yang nantinya akan memberikan positioning dan differentiation dari brand tersebut. Nation branding bertujuan untuk menciptakan reputasi tentang suatu negara di mata audiens internasional, reputasi inilah yang memberikan image negara, jika suatu negara memiliki image yang positif di mata internasional, wisatawan akan tertarik untuk berkunjung ke negara tersebut.

Menurut Anholt (2005:20) elemenelemen dari nation branding saling berkaitan untuk menciptakan gambaran dan persepsi tentang suatu negara, diantaranya adalah (1)
Tourism yang menangkap tingkat ketertarikan turis untuk mengunjungi suatu negara dilihat dari tempat wisata alam maupun buatannya, (2) Culture, karena perkembangan pariwisata sangat terkait dengan perkembangan budaya, sumber budaya yang unik akan menjadi daya tarik wisata, (3) People, Penduduk atau masyarakat yang berada di suatu negara memberikan penilaian akan negara tersebut begitu pula reputasi penduduk, keterbukaan dan tingkat keramahan penduduk.

Selain bertujuan untuk menciptakan persepsi dan gambaran di benar konsumen, tujuan diadakannya nation branding adalah untuk memposisikan suatu negara untuk dapat bersaing di pasar global dan menarik turis dan investor asing.

Menurut Eugenio-Martin (2003:3) sebelum memutuskan ke mana harus pergi pada hari libur, sebagian besar wisatawan harus membuat beberapa keputusan. Bagi sebagian orang keputusan ini direncanakan dengan sempurna, bagi orang lain ini adalah improvisasi atau tidak direncanakan. Selain itu, beberapa orang dapat memutuskan semuanya secara bersamaan atau dalam tahapan yang berbeda. Eugenio-Martin membagi proses keputusan berkunjung menjadi enam tahapan: Participation decision yang merupakan pemikiran dan pertimbangan terlebih dahulu yang menyangkut pilihan untuk berpergian atau tidak dalam kurun waktu tertentu, tourism budget decision dimana wisatawan memutuskan berapa banyak pengeluaran pariwisata yang mungkin akan dikeluarkan, frequency and length of stay decision yang merupakan tahap dimana wisatawan memutuskan seberapa sering dan untuk berapa lama akan tinggal di destinasi pilihan, kind of tourist destination decision tahap dimana wisawatan mempertimbangkan jenis wisata atau destinasi yang diinginkan, apakah memenuhi kriteria dan kebutuhan wisatawan atau tidak, final destination dimana wisatawan mengambil keputusan setelah melaui pertimbangan dan pemikiran tertentu terhadap destinasi yang dipilih, dan tahap mode of transportation choice dimana wisatawan memutuskan sendiri bagaimana cara menuju destinasi yang dituju.

\section{METODE PENELITIAN \\ Penelitian ini dilakukan untuk} menganalisa dan mengukur mengenai kinerja nation branding yang dimiliki 
Indonesia, yakni "Wonderful Indonesia" terhadap proses keputusan berkunjung wisatawan Australia yang berkunjung ke Indonesia. Adapun yang menjadi objek penelitian dalam penelitian ini sebagai variabel bebas atau independent adalah nation branding dan proses keputusan berkunjung sebagai $\mathrm{Y}$ yang merupakan variabel terikat. Adapun yang dijadikan unit responden adalah wisatawan Australia yang masuk melalui bandara internasional Soekarno-Hatta dan Ngurah-Rai. Penelitian ini akan dilaksanakan pada kurun waktu kurang dari satu tahun, maka metode yang digunakan adalah cross sectional method.

Penelitian ini menggunakan jenis penelitian deskriptif dan verifikatif. Menurut Sugiyono (2011:53) penelitian deskriptif adalah "Penelitian yang dilakukan untuk mengetahui keberadaan variabel mandiri baik satu variabel atau lebih (variabel yang berdiri sendiri tanpa membuat perbandingan dan/atau mencari hubungan variabel satu sama lain", sedangkan verifikatif menurut Sugiyono (2012:54), "Penelitian verifikatif adalah penelitian yang membandingkan keberadaan satu variabel atau lebih pada dua atau lebih sampel yang berbeda, atau pada waktu yang berbeda". Penelitian verifikatif bertujuan untuk memperoleh kebenaran dari suatu hipotesis yang dilaksanakan melalui pengumpulan data dilapangan.

Penentuan ukuran sampel (n) dan populasi (N) yang dalam penelitian ini menggunakan rumus sample Slovin (Umar, 2003:141) yaitu sebagai berikut:

Keterangan

$$
\mathrm{n}=\frac{N}{1+N e^{2}}
$$

$\mathrm{n}=$ Ukuran sampel

$\mathrm{N}=$ Ukuran populasi

$\mathrm{e}=$ Presentase kelonggaran penelitian karena kesalahan pengambilan sampel yang masih dapat ditolelir $(\mathrm{e}=0.1)$

Berdasarkan rumus Slovin, maka ukuran sampel pada penelitian ini adalah sebagai berikut:

$\mathrm{n}=\frac{N}{1+N e^{2}}=\frac{870.696}{1+870.696(0,1)^{2}}=98,98 \approx$
100
Berdasarkan hasil dari perhitungan di atas, diperoleh hasil sampel sebesar 98,08 tetapi untuk jaminan keakuratan, sebaiknya sampel ditambah sedikit lebih banyak dari jumlah matematikanya. Berdasarkan ukuran sampel (n) minimal, maka dalam penelitian ini ditetapkan ukuran sampel (n) sebanyak 120 responden agar lebih representatif. Maka dilakukan uji validitas dan reliabilitas.

\section{HASIL PENELITIAN DAN PEMBAHASAN \\ Pengukuran validitas dilakukan pada} 30 orang responden pada 45 item pertanyaan untuk variabel nation branding dan proses keputusan berkunjung mempunyai rata-rata signifikasi 0,00 . Hal ini menyatakan bahwa instrumen penelitian tersebut mempunyai validitas dan dapat digunakan sebagai alat ukur yang benar karena mempunyai validitas kurang dari jika dibandingkan dengan 0,05. Sedangkan hasil reliabilitas tertinggi adalah Proses Keputusan Berkunjung dengan nilai $C \sigma_{\text {hitung }}$ sebesar 0,888 , sedangkan variabel nation branding memiliki nilai $C \sigma_{\text {hitung }}$ sebesar 0,850. C $\sigma$ masing-masing variabel lebih besar dibandingkan dengan koefisien alpha cronbach yang bernilai 0,700 maka instrumen penelitian dinyatakan reliabel atau memiliki tingkat keandalan tinggi.

Setelah uji validitas dan reliabilitas pada 30 responden, kemudian dilakukan lagi penyebaran kuesioner pada 120 responden yang diambil berdasarkan perhitungan Rumus Solvin kemudian dilakukan pengujian hipotesis. Teknik analisis data yang digunakan dalam penelitian ini adalah path analys atau analisis jalur. Analisis jalur digunakan untuk menganalisis pola hubungan antar variabel dengan tujuan untuk mengetahui pengaruh langsung maupun tidak langsung seperangkat variabel bebas terhadap variabel terkait.

Berdasarkan pada penilaian keseluruhan variabel dan indikator nation branding diperoleh hasil rekapitulasi seluruh tanggapan wisawatan yang dapat dilihat pada Tabel 4.1 berikut: 
TABEL 4.1

REKAPITULASI HASIL TANGGAPAN WISATAWAN

TERHADAP NATION BRANDING

\begin{tabular}{|c|l|c|c|c|c|}
\hline No & $\begin{array}{c}\text { Sub } \\
\text { Variabel }\end{array}$ & $\begin{array}{c}\text { Total } \\
\text { Pertanyaan }\end{array}$ & $\begin{array}{c}\text { Total } \\
\text { Skor }\end{array}$ & $\begin{array}{c}\text { Skor } \\
\text { Rata- } \\
\text { rata }\end{array}$ & $\%$ \\
\hline 1 & Tourism & 4 & 1833 & 458.3 & 35.3 \\
\hline 3 & People & 6 & 2451 & 408.5 & 31.5 \\
\hline 2 & $\begin{array}{l}\text { Culture and } \\
\text { Heritage }\end{array}$ & 4 & 1719 & 429.8 & 33.2 \\
\hline \multicolumn{7}{|c|}{ Total } & $\mathbf{1 4}$ & $\mathbf{6 0 0 3}$ & $\mathbf{1 2 9 6 . 6}$ & $\mathbf{1 0 0}$ \\
\hline
\end{tabular}

Sumber: Hasil Pengolahan Data, 2013

Berdasarkan pada Tabel 4.1 di atas, dapat dilihat bahwa sub variabel dari pelaksanaan nation branding yang mendapatkan penilaian tertinggi adalah tourism dengan persentase sebesar 35,3\% dengan skor rata-rata sebanyak 458,3. Hal tersebut karena Indonesia memiliki daya tarik pariwisata yang sangat tinggi, didukung juga dengan kekayaan alam, buatan dan budaya yang melimpah, yang membuat wisatawan ingin mengunjungi Indonesia.

Sedangkan sub variabel yang mendapat penilaian terendah adalah people dengan persentase sebesar $31,5 \%$ dengan skor ratarata 408,5. Hal tersebut disebabkan oleh kurangnya kualitas servis yang diberikan, karena sesungguhnya masyarakat atau penduduk sekitar memainkan peran yang sangat penting dalam pemasaran pariwisata seperti halnya dalam organisasi jasa lainnya.

Berdasarkan hasil pengolahan data dapat dilihat bahwa pelaksanaan nation branding Indonesia secara keseluruhan berada pada kategori tinggi dengan skor sebesar 6003 atau sebesar 71,46\% ( $\frac{6003}{8400} \mathrm{x}$ 100 ). Hal tersebut dikarenakan nilai tinggi yang diperoleh sub variabel yaitu tourism, people, culture and heritage pada nation branding dapat membuat wisatawan Australia ingin berkunjung ke Indonesia.

Berdasarkan pada penilaian keseluruhan variabel dan indikator proses keputusan berkunjung, maka hasil rekapitulasi seluruh tanggapan wisatawan Australia dapat dilihat pada Tabel 4.2 berikut:

TABEL 4.2

REKAPITULASI HASIL TANGGAPAN WISATAWAN TERHADAP PROSES KEPUTUSAN BERKUNJUNG

\begin{tabular}{|c|l|c|c|c|c|}
\hline No & \multicolumn{1}{|c|}{ Sub Variabel } & $\begin{array}{c}\text { Total } \\
\text { Pertanyaan }\end{array}$ & $\begin{array}{c}\text { Total } \\
\text { Skor }\end{array}$ & $\begin{array}{c}\text { Skor } \\
\text { Rata-rata }\end{array}$ & $\%$ \\
\hline 1 & $\begin{array}{l}\text { Participation } \\
\text { Decision }\end{array}$ & 4 & 1813 & 453.3 & 17.6 \\
\hline 2 & $\begin{array}{l}\text { Tourism Budget } \\
\text { Decision }\end{array}$ & 3 & 1317 & 439 & 17 \\
\hline 3 & $\begin{array}{l}\text { Frequency and } \\
\text { Length of Stay }\end{array}$ & 2 & 901 & 450.5 & 17.4 \\
\hline 5 & $\begin{array}{l}\text { Kind of Destination } \\
\text { Decisions }\end{array}$ & 2 & 919 & 459.5 & 17.8 \\
\hline
\end{tabular}




\begin{tabular}{|c|c|c|c|c|c|}
\hline 6 & $\begin{array}{l}\text { Mode of } \\
\text { Transportation } \\
\text { Choice }\end{array}$ & 3 & 1089 & 363 & 14 \\
\hline & Total & 16 & 6874 & 2582.8 & 100 \\
\hline
\end{tabular}

Sumber: Hasil Pengolahan Data, 2013

Berdasarkan Tabel 4.2, dapat dilihat bahwa sub variabel dari pelaksanaan proses keputusan berkunjung yang mendapatkan penilaian paling tinggi adalah kind of destination decisions dengan persentase sebesar 17,8\% dengan skor rata-rata 459,5. Hal ini terjadi karena pada tahap ini wisatawan mempertimbangkan jenis wisata dan destinasi yang diinginkan, apakah akan memenuhi kebutuhan atau tidak. Sedangkan untuk penilaian yang terendah adalah mode of transportation yaitu sebesar 14\%, karena kondisi transportasi di Indonesia kurang baik, bertolak belakang dengan banyaknya destinasi yang dapat dikunjungi.
Berdasarkan hasil pengolahan data dapat dilihat bahwa pelaksanaan proses keputusan berkunjung secara keseluruhan berada pada kategori tinggi dengan skor sebesar 6874 atau sebesar 71,60\% ( $\frac{6874}{9600} \mathrm{x}$ $100)$.

Pengujian hipotesis dihitung dari besarnya koefisien jalur masing-masing variabel. Selanjutnya berdasarkan perhitungan statistik yang didasarkan pada angka-angka dari masing-masing variabel terlebih dahulu dan dilakukan transformasi. Secara lengkap hasil pengolahan data disajikan secara rinci sebagai berikut:

TABEL 4.3

MATRIK KORELASI ANTARA SUB VARIABEL NATION BRANDING DENGAN PROSES KEPUTUSAN BERKUNJUNG KE INDONESIA

\begin{tabular}{|c|c|c|c|c|}
\hline Variabel / Sub variabel & $\begin{array}{c}\text { Proses } \\
\text { Keputusan } \\
\text { Berkunjung } \\
(\mathrm{Y})\end{array}$ & $\begin{array}{c}\text { Tourism } \\
\left(\mathrm{X}_{1.1}\right)\end{array}$ & $\begin{array}{c}\text { People } \\
\left(\mathrm{X}_{1.2}\right)\end{array}$ & $\begin{array}{c}\text { Culture and } \\
\text { Heritage } \\
\left(\mathrm{X}_{1.3}\right)\end{array}$ \\
\hline $\begin{array}{c}\text { Proses Keputusan Berkunjung } \\
(\mathrm{Y})\end{array}$ & 1 & 0,497 & 0,854 & 0,701 \\
\hline Tourism $\left(\mathrm{X}_{1.1}\right)$ & 0,497 & 1 & 0,327 & 0,292 \\
\hline People $\left(\mathrm{X}_{1.2}\right)$ & 0,854 & 0,327 & 1 & 0,425 \\
\hline Culture and Heritage $\left(\mathrm{X}_{1.3}\right)$ & 0,701 & 0,292 & 0,425 & 1 \\
\hline
\end{tabular}

Sumber: Hasil Pengolahan Data, 2013

Berdasarkan hasil matrik korelasi antara sub variabel nation branding dengan proses keputusan berkunjung ke Indonesia pada Tabel 4.3, dapat dilihat bahwa hasil korelasi secara rata-rata signifikansi 0,00 yaitu tourism $(0,497)$, people $(0,854)$, culture and heritage $(0,701)$.

Berdasarkan tabel tersebut dapat diketahui bahwa nilai hubungan antar sub variabel nation branding dengan proses keputusan berkunjung yang memiliki korelasi terbesar adalah people yaitu sebesar 0,854. Koefisien korelasi tersebut menunjukkan bahwa people memiliki hubungan yang signifikan. Hal ini dikarenakan people dalam suatu negara karena memainkan peran yang sangat penting dalam pemasaran pariwisata seperti halnya dalam organisasi jasa lainnya. Hal ini dikarenakan konsumen mengasosiasikan orang yang memberikan layanan sebagai bagian dari produk itu sendiri. Sedangkan sub variabel dengan korelasi terendah adalah tourism $(0,497)$.

Korelasi terbesar antara variabel $\mathrm{X}$ adalah people dan culture and heritage yaitu sebesar 0,425. Koefisien tersebut menunjukkan bahwa antara people dan culture and heritage memiliki hubungan yang signifikan. Hal ini menunjukkan bahwa wisatawan melakukan kunjungan setelah melihat bagaimana kondisi masyarakat di Indonesia dihubungan dengan budayanya.

Berdasarkan hasil korelasi selanjutnya, maka dilakukan Uji Anova untuk melihat pengaruh natiom branding yang terdiri dari tourism, people, culture and heritage terhadap proses keputusan berkunjung 
TABEL 4.4

\section{UJI ANOVA (UJI F)}

\begin{tabular}{|ll|r|r|r|r|r|}
\hline & Model & Sum of Squares & \multicolumn{1}{c|}{ df } & Mean Square & \multicolumn{1}{c|}{ F } & \multicolumn{1}{c|}{ Sig. } \\
\hline \multirow{3}{*}{1} & Regression & 4266.743 & 3 & 1422.248 & 334.223 & $.000^{\mathrm{b}}$ \\
Residual & 493.624 & 116 & 4.255 & & \\
& Total & 4760.367 & 119 & & & \\
\hline
\end{tabular}

Sumber: Hasil Pengolahan Data, 2013

Berdasarkan hasil outpus SPSS 20 pada Tabel 4.4 menunjukkan bahwa nilai $\mathrm{F}$ sebesar 334.223 dengan signifikansi sebesar 0,000 lebih kecil dari 0,05 yang dapat disimpulkan bahwa Ho ditolak, artinya model penelitian nation branding terhadap proses keputusan berkunjung sesuai dengan data yang diuji. Tabel di atas juga menunjukkan bahwa model yang diajukan fit dengan data yang diuji sehingga proses pengujian jalur dapat dilakukan. Pengujian koefisien jalur setiap variabel digambarkan pada tabel berikut ini:

TABEL 4.5

PENGUJIAN KOEFISIEN JALUR

\begin{tabular}{|c|c|c|c|c|c|c|}
\hline & Model & $\begin{array}{r}\text { Unsta } \\
\text { Coe }\end{array}$ & $\begin{array}{l}\text { dardized } \\
\text { ficients }\end{array}$ & $\begin{array}{l}\text { Standardized } \\
\text { Coefficients }\end{array}$ & $\mathbf{t}$ & Sig. \\
\hline & & B & Std. Error & Beta & & \\
\hline & (Constant) & 10.544 & 1.877 & & 5.619 & .000 \\
\hline & $\mathrm{X} 1$ & .284 & .051 & .179 & 5.567 & .000 \\
\hline 1 & $\mathrm{X} 2$ & .900 & .048 & .634 & 18.665 & .000 \\
\hline & $\mathrm{X} 3$ & 1.377 & .122 & .379 & 11.286 & .000 \\
\hline
\end{tabular}

Sumber: Hasil Pengolahan Data, 2013

Berdasarkan Tabel 4.5 di atas, dapat diketahui bahwa dari ketiga sub variabel yang diuji, semua sub variabel signifikan yang masing-masing memiliki signifikansi dibawah 0,05 . Berikut merupakan diagram jalur pengujian hipotesis yang disajikan pada Gambar 1 berikut:

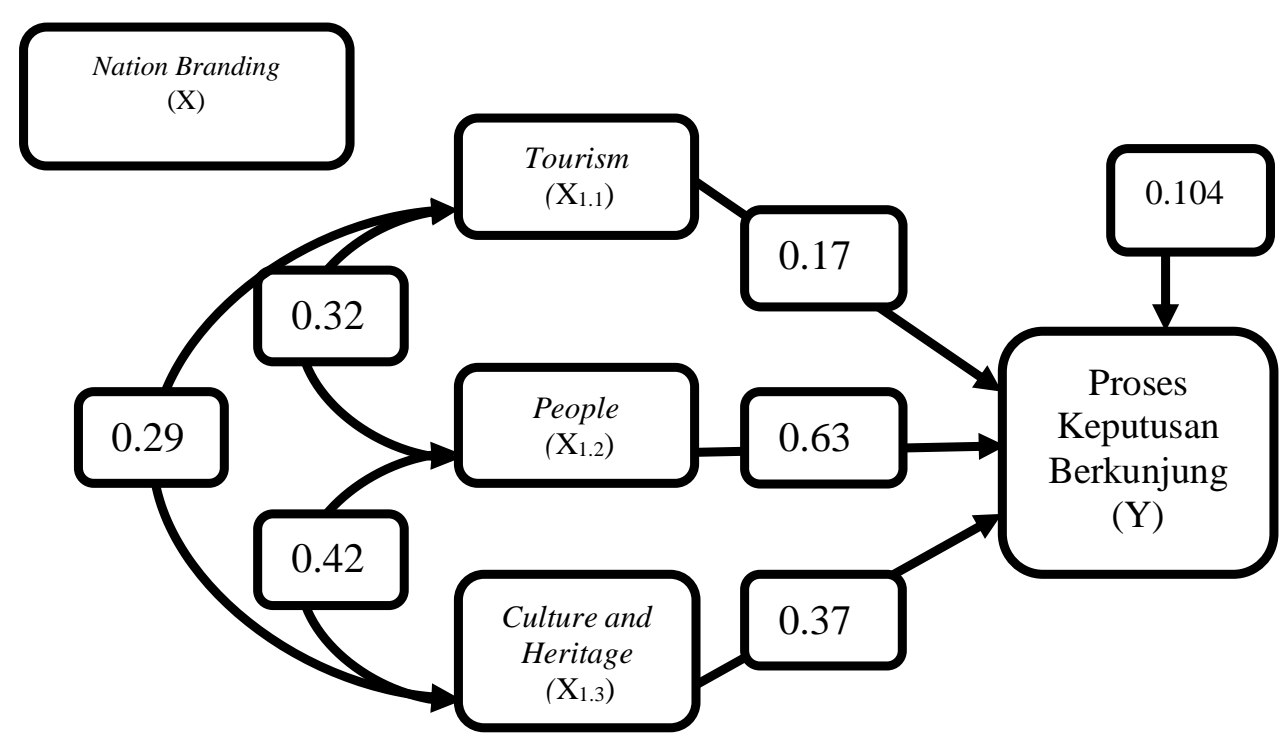


Sumber: Hasil Pengolahan Data, 2013

\section{GAMBAR 4.1 \\ DIAGRAM JALUR PENGUJIAN HIPOTESIS NATION BRANDING TERHADAP PROSES KEPUTUSAN BERKUNJUNG}

Berdasarkan diagram jalur pengujian hipotetis nation branding terhadap proses keputusan berkunjung di atas maka dilakukan perhitungan untuk mengetahui pengaruh langsung dan tidak langsung antar dimensi pada tabel berikut:

TABEL 4.6

HASIL PENGUJIAN KOEFISIEN JALUR, PENGARUH LANGSUNG DAN TIDAK LANGSUNG NATION BRANDING TERHADAP PROSES KEPUTUSAN BERKUNJUNG

\begin{tabular}{|c|c|c|c|c|c|c|c|}
\hline \multirow[t]{2}{*}{$\mathbf{X}$} & \multirow{2}{*}{$\begin{array}{c}\text { Pengaruh } \\
\text { Langsung } \\
\text { Terhadap Y }\end{array}$} & \multicolumn{3}{|c|}{$\begin{array}{c}\text { Pengaruh Tidak } \\
\text { Langsung Melalui }\end{array}$} & \multirow{2}{*}{$\mathbf{R}^{2} \mathbf{Y} \mathbf{X}_{1.1} \mathbf{X}_{1.3}$} & \multirow{2}{*}{ Sig. } & \multirow{2}{*}{ Keputusan } \\
\hline & & $\mathrm{X}_{1.1}$ & $\mathrm{X}_{1.2}$ & $\mathbf{X}_{1.3}$ & & & \\
\hline $\mathrm{X}_{1.1}$ & 0,0320 & - & 0,0371 & 0,0198 & 0,0889 & 0,000 & Ho ditolak \\
\hline $\mathrm{X}_{1.2}$ & 0,4020 & 0,0371 & - & 0,1021 & 0,5412 & 0,000 & Ho ditolak \\
\hline$X_{1.3}$ & 0,1436 & 0,0198 & 0,1021 & - & 0,2655 & 0,000 & Ho ditolak \\
\hline \multicolumn{5}{|c|}{$\mathbf{R}^{2}$} & 0,8956 & & \\
\hline
\end{tabular}

Sumber: Hasil Pengolahan Data, 2013

Pengujian hipotesis melalui signifikansi masing-masing sub variabel menghasilkan penolakan terhadap Ho, yang menunjukkan terdapat pengaruh yang signifikan antara nation branding terhadap proses keputusan berkunjung wisatawan Australia ke Indonesia.

Berdasarkan hasil perhitungan di atas maka dapat disimpulkan bahwa pengaruh nation branding terhadap proses keputusan berkunjung wisatawan Australia ke Indonesia termasuk kategori cukup kuat. Untuk koefisien jalur variabel lainnya di luar variabel $\mathrm{X}_{1.1}$ sampai $\mathrm{X}_{1.3}$ ditentukan melalui perhitungan berikut:

$$
\begin{aligned}
P_{z \varepsilon} & =\sqrt{1-R^{2} Y(X 1, X 2, X 3)} \\
& =\sqrt{1-0,8956} \\
& =0,323
\end{aligned}
$$

Hal tersebut berarti bahwa $X_{1.1}$ sampai $\mathrm{X}_{1.3}$ secara bersama-sama mempengaruhi proses keputusan berkunjung dengan persentase sebesar $89,5 \%$ dan sisanya sebesar $(0,323)^{2}=0,104 \times 100 \%=10,4 \%$ dipengaruhi oleh faktor lain yang tidak termasuk dalam penelitian ini.

\section{KESIMPULAN DAN SARAN}

Berdasarkan hasil penelitian yang telah dilakukan dengan menggunakan analisis deskriptif dan verifikatif dengan menggunakan path analysis antara nation branding dengan proses keputusan berkunjung wisatawan Australia ke Indonesia maka dapat ditarik kesimpulan sebagai berikut :

1. Nation branding di Indonesia mendapatkan penilaian yang tinggi dari wisatawan Australia sesuai dengan garis kontinum nation branding berada pada kategori tinggi. Nation branding itu sendiri terdiri dari tourism, people, dan culture and heritage. Sub variabel yang mendapatkan nilai tertinggi adalah tourism karena Indonesia sudah mampu memposisikan gambaran bahwa pariwisata dan kekayaan alam maupun budaya yang ada di Indonesia dengan baik. Sementara untuk penilaian terendah adalah people karena menurut wisatawan servis yang mereka dapat kurang baik karena kurangnya keterampilan dari karyawan yang ada.

2. Penelitian menunjukkan bahwa sub variabel dari nation branding yang memberikan pengaruh terbesar terhadap proses keputusan berkunjung adalah people, tetapi people mendapatkan penilaian yang cukup kecil dari wisatawan Australia. Hal ini bisa disebabkan kurangnya kepuasan wisatawan akan servis yang diterima.

3. Proses keputusan berkunjung wisatawan Australia ke Indonesia secara umum berdasarkan garis kontinum berada pada tingkat tinggi. Proses keputusan 
berkunjung wisatawan dinilai berdasarkan participation decision, tourism budget decision, frequency and length of stay, kind of destination decision, final destination, dan mode of transportation choice. Berdasarkan hasil penelitian, yang mendapatkan penilaian paling tinggi adalah kind of destination, hal ini disebabkan karena pada tahap ini wisatawan mempertimbangkan jenis wisata dan destinasi yang diinginkan, apakah akan memenuhi kebutuhan atau tidak, tahan ini merupakan tahap sebelum pada akhirnya wisatawan memutuskan untuk berkunjung atau tidak. Sedangkan yang memiliki penilaian terendah adalah mode of transportation choice karena kondisi transportasi di Indonesia kurang baik, bertolak belakang dengan banyaknya destinasi yang dapat dikunjungi.

4. Penelitian memperlihatkan bahwa terdapat pengaruh antara nation branding yang terdiri dari tourism, people, dan culture and heritage terhadap proses keputusan berkunjung wisatawan Australia ke Indonesia. Sehingga dapat ditarik kesimpulan bahwa semakin baik tanggapan wisatawan terhadap nation branding Indonesia maka semakin tinggi proses keputusan berkunjung ke Indonesia.

\section{DAFTAR PUSTAKA}

Anholt, Simon. 2007. Competitive Identity: The New Brand Management for Nations, Cities and Regions. Basingstoke: Palgrave Macmillan.

Dinnie,Keith. 2008. Nation Branding: concepts, issues, practice. Amsterdam: Elsevier.

Direktorat Jenderal Pemasaran. 2013. Rakor Sinkronisasi Program Pemasaran Pariwisata Indonesia 2013. Kemenparekraf

Eugenio-Martin, Juan. 2003. Modelling Determination of Tourism Demand As A 5-Stage Process. A Discrete Choice Methodological Approach. Environment Department University of York. 341-354

Hermawan Kertajaya. 2002. Marketing Plus 2000; Siasat Memenangkan Persaingan Global, Jakarta: Granedia Pustaka Utama.

Husen Umar. 2009. Metode Penelitian Untuk Skripsi dan Tesis Bisini Edisi Kedua. Jakarta : Rajawali Pers.
Lili Adi Wibowo. 2011. Handout Metodologi Penelitian.

Kotler, Philip, Kevin Lane Keller. 2012. Marketing Management $14^{\text {th }}$ Edition. New Jersey : Prentince Hall.

Sugiyono, 2012. Metode Penelitian Kuantitatif Kualitatif dan $R \& D$. Alfabeta : Bandung.

\section{Website:}

Akotia, Mathias. 2010. Nation branding and Nation Image. Feauture article 201011-14. (Accessed 05-07-12/2.35) [http://www.ghanaweb.com/ GhanaHomePage/NewsArchive/artik el.php?ID=197380]

Anholt, Simon. 2012. (accesed 02-0312/5.00)

[Available

at http://www.simonanholt.com ]

Cromwell, T. Why nation brand is important for tourism. (accessed 10-0812/4.45) [Available at http://eastwestcoms.com/WhyNation-Branding-Is-Important- ForTourism.html]

Kementrian Pariwisata dan Ekonomi Kreatif. 2012. (accessed 4-1012/9.55) [Available at http://www.budpar.go.id ]

Markessinis, Andreas. 2010. Nation Branding. (accessed 05-07-12/2.40) [http://nationbranding.info/tag/andreasmarkessinis/ ]

Tolba, Ahmed. 2010. Nation Branding: The Way To Go. (accessed 4-10-12/3.35) [http://www.amcham.org.eg/events_a ctivities/committees/ArticleDetails.as $\mathrm{p}$ ?AI=33]

United Nations for World Tourism Organization (UNWTO). 2012. Perkembangan Pariwisata Indonesia (accessed 20-1-12/08.44) [Available at

http://www.investor.co.id/tourism/un wto-optimis-single-destination-aseanpicu-pariwisata/27916 ] 